\title{
Distraction modality and stimulus modality in paired-associate learning*
}

\author{
FRANK W. WICKER and FREDA M. HOLLEY \\ University of Texas, Austin, Tex. 78712
}

The effects of visual and auditory auxiliary distracting tasks were compared with pictorial and verbal stimuli in paired-associate learning following either standard or imagery instructions. Type of distraction was found to interact with stimulus modality but not with instructional set. The usual superiority of pictorial stimuli was somewhat reduced by auditory distraction and was eliminated by visual distraction. Results were considered in terms of several alternate hypotheses regarding encoding, imagery mediation, and interference.

Perhaps the greatest difficulty faced in the study of imagery mediation in learning concerns the need to make this construct operational so that it can be differentiated from other hypothetical processes such as verbal or motor mediation. The progress made on this problem is documented convincingly by Bower (1970). One promising approach is based on the work of Brooks (1967, 1968), who demonstrated decrements in performance when there was apparent overlap in the modality of information to be remembered and of the input and output operations used in processing that information. For example, tasks of spatial visualization were found to be more difficult when based on reading than when based on listening. His results implied distinct visual and verbal systems of limited capacity, within which there is competition between imaginal processes and corresponding perceptual processes.

This approach has been applied to studies of mediation in associative learning by Atwood (1969) and Bower (1970), with results which support a distinction between visual and verbal mediation. Bower found that, relative to a tactile tracking task, a visual tracking task produced more interference after imagery mediation instructions than after rote repetition instructions. Atwood found that a visual distracting task produced a greater decrement with concrete verbal materials and an auditory task produced a greater decrement with abstract verbal materials, suggesting the primacy of visual encoding in the former case and of verbal encoding in the latter.

* Reprint requests should be sent to Frank W. Wicker, Department of Educational Psychology, University of Texas at Austin. This research was partially supported by a summer grant from the University of Texas Research Institute to the senior author and a U.S. Office of Education research fellowship to the junior author.
In the present study, the effects of visual and auditory distraction were compared with both pictorial and verbal stimuli and with both standard and imagery instruction in paired-associate learning (PAL) in an attempt to obtain data bearing on the issue of whether differences in imagery mediation contribute to picture-word differences in PAL. It has often been observed that pictorial items are superior to corresponding verbal items as stimulus terms in PAL (e.g., Paivio \& Yarmey, 1966; Wicker, 1970a), and this finding has been widely attributed to picture superiority in eliciting imagery mediation (e.g., Reese, 1970 Paivio, 1969). On the other hand, it has been suggested (Wicker, 1971; Wicker \& Evertson, in press) that the picture-word effect sometimes rests entirely on the greater recognizability of picture stimuli and may, in fact, occur despite a subtle word advantage in imagery mediation.

Another explanation of the picture-word effect which will be considered is that pictures are doubly encoded-that they are encoded both visually and verbally - and thus have an advantage over words, which may be encoded only verbally. Double encoding could increase the probability of stimulus recognition during the test trial of PAL and thus could increase recall without any effect on subsequent associative mediation.

\section{METHOD}

The Ss worked with one of two mixed lists of 30 paired associates. Each list contained 15 word-word pairs and 15 picture-word pairs (picture stimuli were representational line drawings). For each picture-word pair in one list there was a corresponding word-word pair in the other. Stimuli were projected onto a daylight screen from $35-\mathrm{mm}$ slides with a Carousel slide projector advanced by an electromechanical timer. The stimulus materials were identical to those used in several previous studies (e.g., Wicker, 1971).

There were two study-test trials of PAL. Half of the Ss (I-set group) were asked to employ "a visual image or a mental picture" to associate the two items of the pair; the other half (S-set group) were instructed simply to form an association, with no suggestion as to rehearsal strategy. Examples were given to clarify the task for both groups. All Ss were instructed that they would have to respond differentially to three types of pairs. No-distraction pairs (N-pairs) were presented for $2 \mathrm{sec}$, followed by $4 \mathrm{sec}$ of uninterrupted study. Visual-distraction pairs (V-pairs) were shown for $2 \mathrm{sec}$, followed by a 2-sec presentation of a simple abstract design and an additional $2 \mathrm{sec}$ in which Ss were to copy the abstract figure as they attempted to rehearse the pair. After auditory-distraction pairs (A-pairs) had been presented for $2 \mathrm{sec}$, E called out a six-digit number which $\mathrm{S}$ was to repeat orally while learning the pair. In all cases, there were 6 sec between pairs. The Ss were instructed to study all pairs while reproducing any additional auditory or visual stimulus that was presented. They were given three practice items, and the necessity of reproducing every distractor stimulus was emphasized. The mixed list of 30 pairs contained six types of pairs in all: five word-word pairs and five picture-word pairs of each distractor type, presented in a randomly determined order.

Five seconds per item were given in recall periods. Each response was placed on the blank side of an IBM card which was then turned face down so that a new card could be used for the next item.

Table 1

Means and Standard Deviations for Number of Correct Responses in Two Trials for Each Type of Paix and Instructional Set

\begin{tabular}{|c|c|c|c|c|c|c|}
\hline & \multicolumn{2}{|c|}{ N Pair } & \multicolumn{2}{|c|}{ A Pair } & \multicolumn{2}{|c|}{ V Pair } \\
\hline & Mean & SD & Mean & SD & Mean & SD \\
\hline $\begin{array}{l}\text { Picture Stimulus } \\
\text { Word Stimulus }\end{array}$ & $\begin{array}{l}4.38 \\
3.33\end{array}$ & $\begin{array}{l}2.34 \\
1.95\end{array}$ & $\begin{array}{r}\text { Standard } \\
3.79 \\
3.29\end{array}$ & $\begin{array}{c}\text { Instructions } \\
2.22 \\
2.35\end{array}$ & $\begin{array}{l}2.50 \\
2.71\end{array}$ & $\begin{array}{l}2.38 \\
2.32\end{array}$ \\
\hline $\begin{array}{l}\text { Picture Stimulus } \\
\text { Word Stimulus }\end{array}$ & $\begin{array}{l}5.75 \\
5.17\end{array}$ & $\begin{array}{l}2.00 \\
2.30\end{array}$ & $\begin{array}{r}\text { Imagery } \\
5.21 \\
4.96\end{array}$ & $\begin{array}{c}\text { Instructions } \\
2.61 \\
2.76\end{array}$ & $\begin{array}{l}3.83 \\
4.21\end{array}$ & $\begin{array}{l}2.54 \\
2.41\end{array}$ \\
\hline
\end{tabular}


Table 2

Means and Standard Deviations for Number of Correct Responses Per Trial for Each Distractor Condition and for Each Stimulus Modality

\begin{tabular}{|c|c|c|c|c|c|c|c|c|c|c|}
\hline \multirow[b]{2}{*}{ Trial } & \multicolumn{2}{|c|}{$\mathrm{N}$ Pair } & \multicolumn{2}{|c|}{ A Pair } & \multicolumn{2}{|c|}{ V Pair } & \multicolumn{2}{|c|}{$\begin{array}{l}\text { Picture } \\
\text { Stimulus }\end{array}$} & \multicolumn{2}{|c|}{$\begin{array}{l}\text { Word } \\
\text { Stimulus }\end{array}$} \\
\hline & Mlean & SD & Mean & $\mathrm{SD}$ & Mean & SD & Mean & $\mathrm{SD}$ & Mean & SD \\
\hline $\begin{array}{l}1 \\
2\end{array}$ & $\begin{array}{l}1.32 \\
3.33\end{array}$ & $\begin{array}{l}1.26 \\
1.37\end{array}$ & $\begin{array}{l}1.15 \\
3.17\end{array}$ & $\begin{array}{l}1.29 \\
1.59\end{array}$ & $\begin{array}{r}.85 \\
2.46\end{array}$ & $\begin{array}{l}1.16 \\
1.56\end{array}$ & $\begin{array}{l}1.11 \\
3.13\end{array}$ & $\begin{array}{l}1.26 \\
1.56\end{array}$ & $\begin{array}{l}1.10 \\
2.84\end{array}$ & $\begin{array}{l}1.24 \\
1.54\end{array}$ \\
\hline
\end{tabular}

After the two trials, Ss were given a postexperimental questionnaire on which they rated their earlier use of imagery for each pair on a scale from 0 (definitely no image) to 4 (a very clear strong image) by circling one of five digits following each pair on their answer sheets.

Forty-eight undergraduate students of educational psychology at the University of Texas at Austin participated as Ss to fulfill a course requirement. They were tested individually and were assigned on arrival to one of four treatment groups, defined by the two instructional sets and the two lists.

RESULTS AND DISCUSSION

The means and SDs for the number of correct responses over two trials for each of six types of pairs with $S$ set and with I set (a maximum value of 10 was possible for each type) are presented in Table 1. A five-way analysis of variance was performed with instructional set, lists, distractor condition, stimulus mode (picture vs word), and trials as factors. There were repeated observations on the last three factors. A main effect for instructional set $(F=6.48, \quad \mathrm{df}=1 / 44, \quad p<.05)$ reflected the greater recall with $I$ set than with $S$ set. An effect for distractor condition $(F=28.14$, $\mathrm{df}=2 / 88, \mathrm{p}<.001$ ) suggested that the distracting tasks impaired performance, especially the visual task. Performance defiritely improved on the second trial ( $F=415.04$, $\mathrm{df}=1 / 44, \mathrm{p}<.001)$.

The overall picture-word difference did not attain significance $(F=3.63$, $\mathrm{df}=1 / 44, .05<\mathrm{p}<.10$ ). That this result does not contradict the usual finding of picture superiority is indicated, however, by the Stimulus Mode by Distraction interaction $(F=4.77, \mathrm{df}=2 / 88, \mathrm{p}<.05)$. Table 1 indicates that picture superiority was obtained when there was no distraction, but the difference was reduced by auditory distraction and totally eliminated or reversed by visual distraction. Tests for simple effects were based on a three-way analysis with instructional set, stimulus modality, and distractor condition as factors and used the pooled error term suggested by Winer (1962, p. 323). A significant picture-word difference was obtained with N-pairs $(F=8.67$, $\mathrm{df}=1 / 46, \mathrm{p}<.01$ ), but not with $\mathrm{A}$ - or $V$-pairs. Picture-word differences in the $\mathrm{N}$-pair condition were significantly larger than those in the $V$-pair condition (Dunnett's $t=3.16$, $\mathrm{p}<.01$ ), but not significantly larger than A-pair differences (Dunnett's $\mathrm{t}=1.06$, n.s.).

No interaction was found between distractor condition and instructional set. This interaction had not been predicted, however, because I set was contrasted with $S$ set rather than with rote repetition instructions. The postexperimental report data given in Table 3 suggest that considerable imagery mediation was employed in both groups (a maximum of five reported images was possible in each cell).

There was a Distraction by Trials interaction $(F=4.82, \quad \mathrm{df}=2 / 88$, $p<.05$ ), even though the order of means for distraction conditions was the same on both trials (Table 2). The Stimulus Mode by Trials interaction $(\mathrm{F}=4.47, \quad \mathrm{df}=1 / 44, \quad \mathrm{p}<.05)$ indicated on the right side of Table 2 suggests that there was little picture advantage until the second trial. This result contrasts with a previous study (Wicker, 1970a) in which significant picture-word differences were found on the first trial but not on the second. Perhaps the overall complexity of the task in the present study prevented effective utilization of encoding strategies for pictures until the second trial.

Our finding that visual distraction has a greater effect with pictorial than with verbal stimuli is consistent with

Table 3

Means and Standard Deviations for Number of Reported Images* for Each Type of $P$ air and Instructional Set

\begin{tabular}{|c|c|c|c|c|c|c|}
\hline & \multicolumn{2}{|c|}{ N Pair } & \multicolumn{2}{|c|}{ A Pair } & \multicolumn{2}{|c|}{ V Pair } \\
\hline & Mean & $\mathrm{SD}$ & Mean & $\mathrm{SD}$ & Mean & $\mathrm{SD}$ \\
\hline & & & Standard & Instructions & & \\
\hline Picture Stimulus & 3.00 & 1.41 & 3.13 & 1.56 & 1.88 & 1.47 \\
\hline Word Stimulus & 2.58 & 1.34 & 2.33 & 1.27 & 1.79 & 1.28 \\
\hline & & & Imagery & Instructions & & \\
\hline Picture Stimulus & 3.46 & 1.07 & 2.88 & 1.42 & 2.46 & 1.35 \\
\hline Word Stimulus & 3.42 & 1.22 & 2.67 & 1.57 & 2.63 & 1.10 \\
\hline
\end{tabular}

*A rating of 2 or greater was defined as a reported image. the hypothesis that more imagery mediation was employed with picture stimuli, so that picture-word pairs were more vulnerable to visual overload than were word-word pairs The subjective report data for the $S$-set group support this hypothesis in that more imagery was reported for pictures unless there was visual distraction. These data are suspect, however, because of evidence that postexperimentally reported images are directly influenced by prior recall (Wicker, 1971; Wicker \& Evertson, in press), so that the high similarity in pattern between number correct and number of reported images may reflect only that influence. Another problem with the image-frequency hypothesis is that the greater visual distractability for pictures was found equally in the I-set condition, although I set virtually eliminated reported picture-word differences in imagery mediation (Table 3).

An alternate possibility is that because line drawings are fixed in a form which may not be compatible with the most effective mediational image for $S$, they may evoke mediation which is less resistant to distraction. Or the visual distractors may increase intralist interference more for pictures than for words. These interpretations do predict as strong an interaction in the I-set group as in the S-set group. The suggestion of a restriction on imagery mediation to pictures also seems more consistent with the findings that (1) picture-word differences in recall can be reversed with imagery instructions and control for recognition (Wicker, 1971), (2) Ss are more fluent in giving sensory associations to words than to pictures (Wicker, 1970b), and (3) more images are reported for words than for pictures during the study period of PAL (Wicker and Evertson, in press).

The fact that auditory distraction had at least as much of a debilitating effect on picture-word pairs as on word-word pairs seems consistent with the double-encoding explanation of picture-word differences. Other explanations are possible: picture pairs may be more susceptible to any distractor regardless of modality, for example, and this factor mav balance the effect of greater verbal encoding 
with word pairs. Still, the double-encoding hypothesis seems most parsimonious.

\section{REFERENCES}

ATWOOD. G. E. Experimental studies in mnemonic visualization. Unpublished PhD dissertation. University of Oregon, 1969

BOWER, G. H. Analysis of a mnemonic device. American Scientist, 1970, 58 . 496-510.

BROOKS, L. R. The suppression of visualization by reading. Quarterly Journal of Experimental Psychology.
1967. 19.289-299.

BR OOKS. L. R. Spatial and verbal components of the act of recall. Canadian Journal of Psychology. 1968, 22 349-368.

PAIVIO, A. Mental imagery in associative learning and memory. Psychological Review, 1969, 76. 241-263.

PAIVIO, A.. \& YARMEY. A. D. Pictures versus words as stimuli and responses in paired-associate learning. Psychonomic Science. 1966,11,137-138.

REESE. H. W. Imagery in children's learning: A symposium. Psychological Bulletin. 1970, $73,383-421$.

WICKER. F. W. On the locus of picture-word differences in paired-associate learning. Joumal of
Verbal Learning \& Verbat Behavior. $1970 a, 9,52-57$.

WICKER, F. W. Continuous restricted associations to pictorial and verbal items Audio-Visual Communication Review $1970 \mathrm{~b}, 18,431-439$

WTCKER, F. W. Pictures, words, and imagery mediation in paired-associate learning. Perceptual \& Motor Skills, 1971. 33, 135-144.

WICKER, F. W.. \& EVERTSON, C. II Prerecall and postrecall imagery ratings with pictorial and verbal stimuli in paired-associate learning. Journal of Experimental Psychology, in press.

WINER, B. J. Statistical principles in experimental design. New York: McGraw-Hill, 1962. 